\title{
Harmful rights-doing? The perceived problem of liberal paradigms and public health
}

\author{
J Coggon
}

J. Med. Ethics 2008;34;798-801

doi:10.1136/jme.2007.024067

Updated information and services can be found at:

http://jme.bmj.com/cgi/content/full/34/11/798

\section{References}

Rapid responses

Email alerting service

\section{These include:}

This article cites 5 articles, 1 of which can be accessed free at: http://jme.bmj.com/cgi/content/full/34/11/798\#BIBL

You can respond to this article at: http://jme.bmj.com/cgi/eletter-submit/34/11/798

Receive free email alerts when new articles cite this article - sign up in the box at the top right corner of the article

Notes

To order reprints of this article go to:

http://journals.bmj.com/cgi/reprintform

To subscribe to Journal of Medical Ethics go to:

http://journals.bmj.com/subscriptions/ 


\title{
Harmful rights-doing? The perceived problem of liberal paradigms and public health
}

\author{
J Coggon
}

Correspondence to:

John Coggon, Centre for Social

Ethics and Policy and Institute

for Science, Ethics and

Innovation, School of Law,

University of Manchester,

Oxford Road, Manchester M13

9PL, UK; John.Coggon@

manchester.ac.uk

Received 15 December 2007

Accepted 3 March 2008

\section{ABSTRACT}

The focus of this paper is public health law and ethics, and the analytic framework advanced in the report Public health: ethical issues by the Nuffield Council on Bioethics. The author criticises the perceived problems found with liberal models associated with Millian political philosophy and questions the Report's attempt to add to such theoretical frameworks. The author suggests a stronger theoretical account that the Council could have adopted-that advanced in the works of Joseph Razwhich would have been more appropriate. Instead of seeking to justify overruling the legitimate interests of individuals in favour of society, this account holds that the interests are necessarily interwoven and thus such a conflict does not exist. It is based on an objective moral account and does not require an excessive commitment to individuals' entitlements.

In this paper, I consider the question of finding an appropriate theoretical framework to use in analysis of public health policy. I focus on a recent report of the Nuffield Council on Bioethics, ${ }^{1}$ in which a "stewardship model" is advocated as the appropriate means for assessing the state's public health responsibilities. This is intended to be distinguished from legitimacy judged by reference to John Stuart Mill's "harm principle", which the Report found to be too individualistic in its focus. I argue first that the Report's framework fails to add anything analytically useful to the Millian framework. I then argue that given the concerns raised in the Report regarding a clash between individual and community interests, a stronger framework would have been appropriate. I suggest that a liberal model advanced by Joseph Raz would be suitable, as it is rooted in objective morality and ties the individual and public good together, rather than positing them as being at odds with each other.

\section{UNEASE WITH THE STATUS QUO}

In politicolegal and bioethical discourse in the UK, an evolution from Millian liberalism ${ }^{2}$ has been seen to underpin much doctrine that supports healthcare law and policy. For the purposes of this paper, I shall refer to this liberalism as the Millian paradigm. Briefly, it holds that any unwanted interference with a competent person's choices cannot be justified by reference to that person's own good: individuals are sovereign of themselves, and may not be interfered with except to protect others from harm. There is, however, no concomitant commitment requiring the state to provide people with everything they demand to achieve all that they might wish. The commonly cited distinction between positive and negative freedom is fundamental. ${ }^{3}$ Key judicial decisions ${ }^{4}{ }^{5}$ and acts of Parliament (such as the Mental Capacity Act 2005) rest on premises compatible with such liberalism. The distinction between positive and negative freedoms allows healthcare law to prohibit some consensual harms administered between adults, ${ }^{6}$ but not if execution of such harms entails what counts at law as an omission. ${ }^{7}$

For some analysts, this situation is problematic. The pluralist outlook that the liberalism is sometimes argued to support is seen to sustain, perhaps even give nourishment to, a hyperindividualistic, rights-based system in which the self-government, or inviolability, of the individual is afforded disproportionate importance. Despite a growing backlash against this from eminent academics writing in the field of bioethics, ${ }^{8-11}$ individual autonomy understood as mere action in accordance with any second-order (and often even firstorder) desire still seems to reign, in principle if not always in practice. ${ }^{12}$ For analysts who simply reject the cogency of the Millian paradigm, it is possible to argue explicitly against it and to suggest a complete shift in the ethical underpinnings to healthcare policy.

An associated but trickier problem exists for those less willing to be so overtly opposed to the Millian paradigm but who find the paradigm hard to apply as a universal framework. A perennial difficulty for many (though not all) liberal pluralists is the clash between the apparent valueagnosticism their theories support and the need for some definite notions of the good on which deference to individuals' higher wisdom is unworkable. ${ }^{13}$ In other words, they support a society in which people can make choices for themselves without fear of paternalist intervention from the state, but, to avoid anarchy, they also require some rules that cannot be waived, no matter what individuals may think. This is in part to allow social interaction to work at all, and in part because society is not composed of purely rational, autonomous agents, so some paternalism is necessary (eg, to protect children, or the mentally disabled). In the context of public health law and ethics, this problem is particularly acute: "good" public health measures seem naturally suited to communitarian or republican models rather than to a liberal model that supports the individual's freedom from interference. ${ }^{14}$

In this paper, I consider the report of the Nuffield Council on Bioethics, entitled Public health: ethical issues (referred to hereafter as the Nuffield Report). ${ }^{1}$ This provides a useful example of an ethical framework whose principled critique of the Millian paradigm seems to feel the need to 
apologise for departing from it. In the Nuffield Report, the Millian paradigm is used as the basis of legitimate state measures, but where the conclusions are found to be unsatisfactory, it is set to one side. In the following sections of this paper, I criticise this approach to public health ethics. It is preferable, I argue, either to reject or accept a particular model. Although theorists may legitimately draw from other works without actually adopting them, I suggest that it is possible, and more satisfactory, to employ a normative framework that is less apologetic for its use and has stronger appeal to the factors that give it legitimacy.

\section{THE NUFFIELD REPORT}

The Nuffield Report comes out at a time when public health ethics is really coming to the fore as a crucial focus of bioethical study. For example, an increasing number of publications, ${ }^{15-18}$ and a new journal called Public Health Ethics, are drawing the interest of commentators with a broad range of concerns. Works on health policy span a spectrum from those who fear health may be used as a tool for tyranny, and thus fear cynical interferences with individuals' liberty, ${ }^{19}{ }^{20}$ to those concerned that states have a duty to interfere for the good of people, perhaps even in the face of reluctance or resistance. ${ }^{17}$ This spectrum is described in the Nuffield Report (pp13-14) ${ }^{1}$ as extending from libertarianism (giving the state the mandate only to protect people's "natural rights" to enjoy life, liberty and property) to collectivism (giving the state the mandate to maximise collective utility, or to legislate in reflection of the collective will of the community). (The Report does acknowledge that principled accounts are more subtly varied than this, but this is a useful analytic picture.)

The Nuffield Report places liberalism somewhere in between the extremes, describing the understanding of what it calls "the liberal state" as follows:

The liberal agrees with the libertarian that the protection of individual freedom constrains the state's authority. Nonetheless, the liberal rejects the libertarian thesis that legitimate state power is restricted to protection of these freedoms, and agrees with the social contract version of collectivism that the state's power may rightly be used to advance the welfare of its citizens. (p14)

The tension that is felt by some to exist between personal autonomy and general welfare is, as we have seen, hard to reconcile. The Millian paradigm is advanced in the Nuffield Report, under the name of the harm principle, and is explored as a means of serving public health. The Report notes that the Millian paradigm permits that vulnerable people such as children be protected from harming their health, is consistent with a concern for general welfare and is consistent with measures taken to educate and inform people so that they can make their own choices (p17) ${ }^{1}$. However, the Report finds that:

Critics may feel that despite the acknowledgement here of the importance of public goods and services, this framework remains too strongly committed to individual autonomy. $(\mathrm{p} 18)^{1}$

The Report does not satisfactorily support this claim. The Millian paradigm, though correctly seen to underpin individual healthcare, is not a framework derived to cater solely for such matters. Mill's On liberty is an essay aimed at good governance wholesale. Although individualistic interpretations of autonomy have developed on the back of the freedoms enunciated in his work, they are by no means its only interpretation.
Therefore, we would do well to question the very idea suggested in the Nuffield Report that the Millian paradigm is unfit

to recognise the difference between consent requirements that are relevant in the context of clinical medicine and research, and those for infringements of people's choices or liberties in the nonclinical context of public health. (p19)

Nevertheless, the Nuffield Report works on the basis that the Millian paradigm is of too narrow application, and thus looks towards "adding a social dimension" (p23).

Described in the spirit of compromise, the Report advocates a "revised liberal framework", called the "stewardship model". This is argued to sit between paternalism and individualism, and "means that liberal states have responsibilities to look after important needs of people both individually and collectively" (p25). ${ }^{1}$ This focus on the collective good, the Report suggests, is not found in the Millian paradigm. It is argued that the stewardship model incorporates the Millian paradigm. Where possible, this is to be used, but where it is (for whatever reason) inappropriate, stewardship kicks in. The Report says at page 145:

[I]n some situations both consent and autonomy may have to be accorded less importance in public health ethics than they would in, for example, clinical medicine. Existing bioethics frameworks are often, therefore, not well suited to address the problems that arise in public health. Much of the literature on ethics in clinical medicine and research tends to focus on the protection of the individual, whereas in the examples considered in this Report, conflicts arise when the behaviour of some individuals has an impact on others.

It goes on to say:

The individual-centred approach that has often dominated bioethical and political discussions has meant that considerations of the 'greater good' are often swept aside as somehow unethical, because they are viewed as incompatible with respect for individuals and their autonomy ... These may be based on respect for the vulnerable, the value of community or other facets of the stewardship model ... This has been accepted historically where policy has focused on ensuring healthy and safe work and living environments, but it may be more difficult in the context of personal behaviour and health, as the examples in this Report have shown.

It is not clear why this demonstrates a need to reject the Millian paradigm, or a framework based on it. The first quotation here seems concerned precisely with the harms being done to others. And the second need not require a modified framework. At most, it seems to require analysts not to be too narrow in their assessment of a measure's legitimacy. In fact, if we take the Nuffield Report's list of stewardship's core characteristics in regard to public health programmes, it is quite hard to see what it adds to require modification to the Millian paradigm (which, we should remember, is only intended to hold once an adequate social situation obtains in which to keep this kind of check on government):

Concerning goals, public health programmes should:

- aim to reduce the risks of ill health that people might impose on each other;

- aim to reduce causes of ill health by regulations that ensure environmental conditions that sustain good health, such as the provision of clean air and water, safe food and decent housing; - pay special attention to the health of children and other vulnerable people; 
- promote health not only by providing information and advice, but also with programmes to help people to overcome addictions and other unhealthy behaviours;

- aim to ensure that it is easy for people to lead a healthy life, for example by providing convenient and safe opportunities for exercise;

- ensure that people have appropriate access to medical services; and

- aim to reduce unfair health inequalities.

In terms of constraints, such programmes should:

- not attempt to coerce adults to lead healthy lives;

- minimise interventions that are introduced without the individual consent of those affected, or without procedural justice arrangements (such as democratic decision-making procedures) which provide adequate mandate; and

- seek to minimise interventions that are perceived as unduly intrusive and in conflict with important personal values. (p26)

I do not wish to be overly critical of the Nuffield Report. It is understandable that there is a feeling that the Millian paradigm falls short of many of these measures if one focuses solely on bioethical literature that looks at patient rights. However, considering On liberty as a broader piece of political philosophy, which it is, it is entirely unclear why the Report could not merely have proposed these goals and constraints as encompassed by a better understanding of Mill than has hitherto been recognised by many analysts. The goals suggested in the Nuffield Report could each be advanced as policy and there is no reason to suppose that they need be precluded if that policy is to be tested against the Millian paradigm.

In the following section, I draw on an account of the link between individual freedom and the public good that is developed in the works of Joseph Raz. Although I tend towards a more morally agnostic account of liberalism ${ }^{21}$ that, it seems to me, Raz would not endorse (see his chapter on liberalism, scepticism, and democracy), ${ }^{22}$ I see much in his account that would support the Report's position on its terms. It is my contention that the Nuffield Report's ethical position would have been stronger had it allied itself to a careful theoretical account of liberalism such as Raz's, which is grounded in an account of objective morality (see his chapter on rights and individual well-being), ${ }^{23}$ rather than simply providing the ends that seem important as justification in themselves for legitimate restrictions on freedom.

\section{RAZ'S LIBERALISM AND THE PUBLIC GOOD}

Liberal accounts need not shirk from questions of objective goods. Joseph Raz has expressed his concern with liberals who link epistemic uncertainties with a need to be absolutely deferential or non-committal about moral positions. Raz's works are of interest here for two reasons. First, it seems to me that they provide the coherent basis to the ideas advanced in the Nuffield Report that seem to be lacking in the Report's own analysis. Second, as Raz is addressing in his writings not bioethics, but political philosophy more broadly, he need not be associated with concerns regarding hyper-individualistic accounts of the Millian paradigm that have proliferated in the bioethical literature. I contend that the Nuffield Report's moral dictates relating to legitimate interferences with individual freedoms, and provision of welfare measures, would have been more compelling had they explicitly tied themselves to arguments such as Raz's. These allow us to remain within a liberal framework without having to worry about making concessions to those who support the Millian paradigm. Raz's liberalism is an example of a political philosophy that does not apologise to supporters of the Millian paradigm who overemphasise the individual, but instead suggests a reappraisal of the appropriate limits of the freedoms that should be permissible.

In his chapter on rights and individual well-being, ${ }^{23} \mathrm{Raz}$ provides a persuasive argument that ties together freedoms afforded in liberal democracies and the public good that this serves. The justification, Raz suggests, for holding fundamental civil and political rights derives from the public good they serve, rather than simply the good of people individually. His account is rich, and the brief summary of it here fails to do it full justice. Nevertheless, it is instructive. Raz ponders the apparent imbalance one sees in many "fundamental" rights that individuals hold-for example, property rights in things that seem valueless, or rights to free expression - and the weight that is given to protection of the individual's interests in having these rights protected. He suggests that the reason that we protect such rights is not really to do with the value that people might derive from, for example, apparently worthless property or from being able to say they disagree with some political regime. Instead, the importance to the common good of allowing such rights is what justifies the heavy premium being placed upon them:

\begin{abstract}
Their real value is in their contribution to a common liberal culture. That culture serves the interests of members of the community ... [I] n the case of the central civil and political rights of liberal societies, the main reason for the mismatch between the importance of the right and its contribution to the rightholder's well-being is the fact that part of the justifying reason for the right is its contribution to the common good. $(\mathrm{p} 55)^{23}$
\end{abstract}

If the Nuffield Report had taken this understanding of liberalism as its core framework, instead of the perhaps simplistic goals advanced under the name of the stewardship model, it would have provided a more compelling, principled account of why liberals should "depart" from their understanding of a sound political philosophy in favour of higher levels of welfare, or even some coercive measures. After all, if we are to be persuaded that the Nuffield Report's framework should be adopted because the ends it seeks to protect are "good", we do not need to worry about a Millian, or any other, framework. We just need a means of assessing the goodness of any policies, based on the matters presented in the Report as important (such as reducing health inequalities, protecting vulnerable groups). Working within a true framework, such as one based on Raz's liberalism, would provide an intellectually coherent basis for freedom-affecting policy measures. The stewardship model simply leaves one guessing whether or not it should be applied. Although there will be disagreement about the application of Raz's liberalism too, it is much more comfortably described as a framework. Thus, where we protect individuals in a way that seems to make them inviolate-for example, by affording them the right to refuse medical treatment for any or no reason-

this is not because in some matters the interest of the individual or the respect due to the individual prevails over the interest of the collectivity or of the majority. It is because by protecting the right of that individual one protects the common good ... (p53) ${ }^{23}$

So, in accordance with this theory, strong negative rights to protect individual autonomy may justifiably be overridden-for example, to support public health measures. (As, of course, they may be under existing law: Public Health (Control of Diseases) Act 1984.) The principled legal argument thus is already won. Policy-makers do not need a new framework, even if they need a new understanding of the best way of fitting law into it. 


\section{CONCLUSIONS}

There is no doubting the value of the Nuffield Report, or the importance of the matters that it puts under the spotlight: there is a real need for the development of a coherent and defensible framework for public health policy, and ideally it is one that is compatible with assessment of policy more generally. Otherwise, we only achieve very local analyses that cannot be said to have universal application. In this paper, I have questioned the strength of the framework that is suggested in the Nuffield Report, which seeks to differentiate itself from the Millian paradigm. I have argued that the public health ends that the Report seeks to meet could arguably be compatible with the Millian paradigm without modification. If this is accepted, the goals set out in the Report need only be advanced as policy measures, and, assuming that overall there is good reason to adopt this policy, they can be brought in. However, if we accept this, we also see that the Report provides less of a framework, and more of a list of ideal targets for policy.

Because a framework might be desirable that is distinct from the Millian paradigm as it is commonly understood, I have gone on to argue that the Report would have been strengthened by use of a carefully developed account of liberalism such as that advanced by Joseph Raz. This is based on objective morality, but ties together the individual and public good, rather than casting them as being at odds with each other. Conceptions of legitimate freedoms under an account such as this would provide a framework that requires limits to be put on people's freedoms without having to imply that a necessary conflict is being tested. It would also obviate the perceived need to apologise for departing from the Millian paradigm in matters relating to health policy. As a framework for public health, I suggest that this is a more satisfactory way forward.

Acknowledgements: Thanks to Sheelagh McGuinness for comments on an earlier draft of this paper. I gratefully acknowledge the support of the British Academy Postdoctoral Fellowship Scheme.
Competing interests: None.

\section{REFERENCES}

1. Nuffield Council on Bioethics. Public health: ethical issues. London: The Council, 2007.

2. Mill JS. On liberty. Alexander E, ed. Peterborough, Ontario: Broadview Press, 1999

3. Berlin I. Two concepts of liberty. In: Four essays on liberty. Oxford: Oxford University Press, 1969.

4. Re T (Adult: Refusal of Treatment) [1993] Fam 95.

5. $\quad R$ (On the Application of Oliver Leslie Burke) v. The General Medical Council [2005] EWCA Civ 1003.

6. $\quad R$ v. Cox [1993] Medical Law Review 1993;1:232.

7. Ms B v. An NHS Hospital Trust [2002] 2 All ER 449.

8. Brazier M. Do no harm-do patients have responsibilities too? Camb Law J 2006;65:397-422.

9. Montgomery J. Law and the demoralisation of medicine. Legal Studies 2006;26:185-210.

10. O'Neill 0. Autonomy and trust in bioethics. Cambridge: Cambridge University Press, 2002.

11. Evans HM. Do patients have duties? J Med Ethics 2007;33:689-94.

12. Coggon J. Varied and principled understandings of autonomy in English law: justifiable inconsistency or blinkered moralism? Health Care Anal 2007;15:235-55.

13. Curtis WM. Liberals and pluralists: Charles Taylor vs John Gray. Contemporary Political Theory 2007;6:86-107.

14. Beauchamp DE. Community - the neglected tradition of public health. In: Bayer R, Gostin LO, Jennings B, et al, eds. Public health ethics: theory, policy, and practice. Oxford: Oxford University Press, 2007:45-56.

15. Bayer R, Gostin LO, Jennings Bruce, et al, eds. Public health ethics: theory, policy, and practice. Oxford: Oxford University Press, 2007.

16. Dawson A, Verweij M. Ethics, prevention, and public health. Oxford: Oxford University Press, 2007.

17. Gostin L0. Public health law: power, duty, restraint. Berkley, Los Angeles, London: University of California Press, 2000.

18. Powers M, Faden R. Social justice: the moral foundations of public health policy. Oxford: Oxford University Press, 2006.

19. Skrabanek P. The death of humane medicine and the rise of coercive healthism. Bury St Edmunds: St Edmundsbury Press, 1994.

20. Fitzpatrick M. The tyranny of health: doctors and the regulation of lifestyle. London: Routledge, 2001.

21. Gray J. Isaiah Berlin. Princeton: Princeton University Press, 1996.

22. Raz J. Liberalism, scepticism, and democracy. In: Raz J. Ethics in the public domain. Oxford: Clarendon, 1994:97-124.

23. Raz J. Rights and individual well-being. In: Raz J. Ethics in the public domain. Oxford: Clarendon, 1994:44-59. 